\title{
Incidence rate of osteoporotic hip fracture in Qatar
}

\author{
Omar Suhail Alsaed ${ }^{1} \cdot$ Nabeel Abdulla $^{1} \cdot$ Abdo Lutf $^{1} \cdot$ Ibrahim Abdulmomen $^{1} \cdot$ Fiaz Alam $^{1} \cdot$ Samar A. Razaq Alemadi ${ }^{1}$
}

Received: 20 June 2021 / Accepted: 23 September 2021 / Published online: 5 October 2021

(c) The Author(s) 2021

\begin{abstract}
Summary The incidence rate of osteoporotic hip fracture is essential to formulate a national fracture risk assessment tool (FRAX). In this epidemiological study, the incidence rate of osteoporotic hip fracture in Qatar was comparable to that in regional countries, and lower than that in North America and European countries.

Purpose Estimate the annual incidence rate (IR) of osteoporotic hip fractures (OHF) in Qatar from January 2017 to December 2019.

Methods Hamad Medical Corporation is a government-based tertiary medical institute. Hip fractures were captured by using the International Classification of Diseases-10 hip fracture codes. The patient records were reviewed retrospectively to identify fracture mechanisms. The observed census in 2017 and the estimated censuses of 2018 and 2019 were used to calculate the age-sex-specific annual IR of OHF in the population aged $\geq 40$ years. The world population in 2010 was used to calculate the age-adjusted standardized IR in the population aged $\geq 50$ years.

Results In total, 458 hip fractures were identified; $75(16.4 \%)$ were due to high-energy trauma, and 9 (2\%) were pathological hip fractures. The total number of OHF was 374 (81.7\%). OHF was slightly higher in men $(215,57.5 \%)$. The median age (IQR) of the patients was 69 years (56-78 years). In 2017, 2018, and 2019, the age-adjusted standardized IR of OHF per 100,000 with the corresponding 95\% CI was 141.7 (141.1-142.2), 140.8 (140.2-141.3), and 162.7 (162.0-163.2) for the whole Qatar population; 154.2 (153.6-154.7), 105.2 (104.7-105.7), and 176.6 (175.9-177.1) for Qataris; and 134.8 (134.3-135.4), 183.9 (183.3-184.6), and 160.4 (159.8-161.0) for non-Qataris, respectively.

Conclusion The annual age-adjusted standardized IR of OHF per 100,000 inhabitants aged $\geq 50$ years in Qatar was comparable to that in regional countries, and lower than that in North America and European countries.
\end{abstract}

Keywords Osteoporosis $\cdot$ Hip fracture $\cdot$ Osteoporotic fracture $\cdot$ Age-sex-specific incidence rate $\cdot$ Age-adjusted standardized incidence rate

\section{Introduction}

Osteoporosis is a global health problem, which is associated with fragility fractures of the spine, hip, humerus, and wrist. Hip fracture is a devastating incident that carries a high mortality rate, negatively affects the quality of life of survivors, and burdens the economy of the health care system $[1,2]$. Following a hip fracture, 40 to $60 \%$ of patients recover their pre-fracture mobility status, $40-70 \%$ regain their level of independence for basic activities of daily living, and 10-20\%

Omar Suhail Alsaed

Omarsohil@hotmail.com; Oalsaed@hamad.qa

1 Division of Rheumatology, Department of Medicine, Hamad Medical Corporation, Alrayyan Street, PO BOX 3050, Doha, Qatar are institutionalized following fracture [3]. It is estimated that the incidence of hip fracture is projected to increase by $240 \%$ in women and $310 \%$ in men by 2050 [4]. The Asian Federation of Osteoporosis Societies study showed that the incidence of hip fracture is expected to increase by 2.28 -fold in 2050 [5].

The incidence rate of osteoporotic hip fracture is one of the essential indices used to predict the probability of fragility fractures and can be used to formulate a national fracture risk assessment tool (FRAX). Most osteoporosis society recommendations favor the use of the FRAX tool to determine the threshold for commencing osteoporotic treatment for each population [6]. There is a large variation in the incidence of hip fractures among different countries and regions worldwide [7]. Based on the available published reports, the incidence is highest in Scandinavian and 
European countries $(>350$ per 100,000$)[8,9]$ and lowest in African countries $(<100$ per 100,000) [10-13]. More hip fracture data are being published in the Middle East and Arab countries. Accumulating data over several decades is essential to provide a broad insight into the probability of fragility fracture rather than simply having data from one country at one point in time.

The structure and number of the Qatar population have changed dramatically over the last 20 years. In 2005, the Qatar population was around 668,629, while in 2017, the Qatar population was 2.7 million, the majority of whom were expatriates from different countries. This figure was obtained from "Qatar Population and Employment Projections 2017-2024-a framework for national planning."

The aim of this study was to estimate the incidence rate of osteoporotic hip fractures in the Qatar population from January 2017 to December 2019. We believe that these data will help policymakers to formulate future plans for osteoporosis management and fragility fracture prevention.

\section{Materials and methods}

\section{Study settings}

Hamad Medical Corporation (HMC) is a government-based non-profit medical institute that provides medical care to all people in different municipalities of Qatar. The electronic medical records (EMRs) of all hospitals operated by HMC (Hamad General Hospital, Al Wakra Hospital, and Al Khor Hospital) were electronically linked by Cerner®. Each citizen and non-citizen resident in Qatar has a unique health care number. The present study included all adult patients aged $\geq 40$ years who presented to the outpatient clinics and emergency room, or were admitted with hip fracture between January 2017 and December 2019.

\section{Case identification}

The International Classification of Diseases (ICD-10) was used for disease coding in all hospitals operated by HMC. Hip fractures were captured by identifying ICD-10 hip fracture codes (S72.0, S72.1, and S72.2) for individuals aged $\geq 40$ years from January 2017 to the end of December 2019. The EMR of these patients was retrospectively reviewed to identify patient demographic data, and the incidence of low-energy trauma hip fractures, high-energy trauma hip fractures, and pathological hip fractures. The standard definition of a low-trauma hip fracture was used to define osteoporotic hip fracture. Low-energy trauma hip fracture was defined as trauma arising from falling from standing height, or trauma, which, in a healthy individual, would not have resulted in a fracture. Pathological fractures
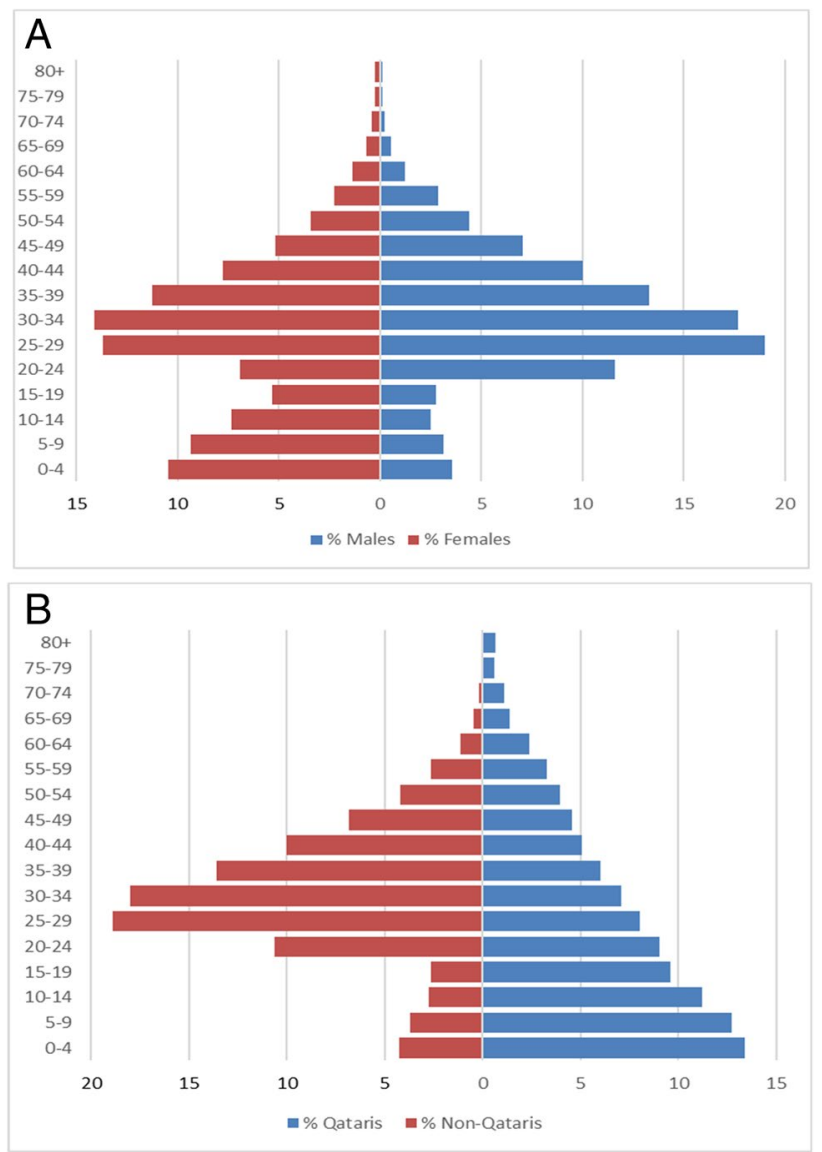

Fig. 1 A Qatar population age pyramid based on the 2017 observed census. B Qatar population distributed according to Qataris and nonQataris based on the 2017 observed census

were not considered osteoporotic fractures. Patients who were visitors to Qatar when they developed hip fracture were excluded.

\section{Incidence rates and standardized incidence rates}

Age-sex-specific incidence rates for 2017-2019 were defined as the yearly number of new osteoporotic hip fracture events divided by the number of individuals from the same sex and age group. To identify the possible impact of age on the observed trends in incidence rates over time, age groups were classified at 5-year intervals starting from 40 years and ending with 80 years and above $(80+)$. The population census provided by the book "Qatar Population and Employment Projections 2017-2024-a framework for national planning" was used to calculate the annual age-sexspecific incidence rate of osteoporotic hip fracture. The 2017 census involved observed data, while the 2018 and 2019 censuses comprised estimated data, according to the projection mentioned in the framework. Figure 1A shows Qatar population age pyramid based on the 2017 observed census. 
Figure 1B shows Qatar population distributed according to Qataris and non-Qataris based on the 2017 observed census. To enable comparisons with other populations, the incidence rates were standardized to the world population of 2010, using the numbers reported by the United Nations (UN) (esa. un.org/unpd/wpp/). The age-adjusted standardized incidence rate with the corresponding $95 \%$ confidence interval (CI) was calculated as described in the statistical methods in the medical research book [14].

\section{Statistical analysis}

The incidence rate and age-adjusted standardized incidence rate of hip fracture were estimated and presented in per 100,000 populations according to age, sex, and Qataris and non-Qataris of the target populations. Specific incidence rates were presented along with $95 \%$ confidence interval (CI) to measure the precision of point estimate value. Descriptive statistics were used to summarize demographic and parameters related to hip fractures. The normally distributed data and results were reported as the mean and standard deviation (SD), and the remaining results were reported as median and interquartile range (IQR). Categorical data were summarized using frequencies and percentages. All statistical analyses were performed using the statistical packages SPSS 27.0 (IBM Inc.; Armonk, NY, USA) and Epi-info (Centers for Disease Control and Prevention, Atlanta, GA) software.

\section{Ethical approval}

This study was approved by the Medical Research Center of HMC under protocol number 01-21-489, and waiver consent was used to extract data from the subjects' medical records.

\section{Results}

\section{Demographic and hip fracture event characteristics}

Over the study period, a total of 458 hip fracture events were identified; among which, 383 (83.6\%) were low-energy trauma hip fractures, and $75(16.4 \%)$ were high-energy trauma hip fracture events. Nine pathological hip fracture events were identified among the low-energy trauma hip fractures. The total number of osteoporotic hip fracture events was $374(81.7 \%)$. The median age of the patients (IQR $25^{\text {th }}-75^{\text {th }}$ ) was 69 years (range, $56-78$ years), with a slight male predominance $(215,57.5 \%)$. Table 1 shows the demographic characteristics and details of the identified hip fracture events during the study period (2017-2019).
Table 1 Demographic characteristics of hip fracture events over the study period 2017-2019

\begin{tabular}{ll}
\hline Variables & \\
\hline Median (IQR $\left.25^{\text {th }}-75^{\text {th }}\right)$ age, years & $69(56-78)$ \\
Sex, males $n(\%)$ & $215(57.5 \%)$ \\
IIQataris, $n(\%)$ & $141(37.7 \%)$ \\
IExpatriates, $n(\%)$ & $233(62.3 \%)$ \\
Total number of hip fracture events, $n$ & 458 \\
Low-energy hip fracture events*, $n(\%)$ & $383(83.6 \%)$ \\
High-energy hip fracture events, $n(\%)$ & $75(16.4 \%)$ \\
Pathological hip fracture events, $n(\%)$ & $9(2 \%)$ \\
Total number of osteoporotic hip fracture events, $n$ & $374(81.7 \%)$ \\
Osteoporotic hip fracture events in 2017 & 112 \\
Osteoporotic hip fracture events in 2018 & 126 \\
Osteoporotic hip fracture events in 2019 & 136 \\
\hline
\end{tabular}

*Low-energy hip fracture includes both osteoporotic hip fracture and pathological hip fracture. $I Q R$, interquartile range

IINumber of individuals who developed osteoporotic hip fracture

\section{Age- and sex-specific incidence rate of osteoporotic hip fracture}

Females had a higher incidence rate in all age groups $>50$ years, except in the age group between 70 and 74 years, in which the mean incidence rate in men was higher than that in women. As expected, the highest incidence rate was observed in the $\geq 80$ years age group, and the lowest was observed in the $\leq 50$ years age group. Table 2 shows the age-sex-specific incidence rate of osteoporotic hip fracture per 100,000 people distributed according to Qataris vs. non-Qataris with the corresponding 95\% CI.

Qatari females had a higher incidence rate of osteoporotic hip fracture in all age groups $(<65-69$ years) than nonQatari females. Both non-Qatari males and females had greater incidence rates in age groups $\geq 70-74$ years compared to Qatari males and females.

\section{Age-adjusted standardized incidence rate of osteoporotic hip fracture}

The annual age-adjusted standardized incidence rate of osteoporotic hip fracture per 100,000 for the population aged $\geq 50$ years with the corresponding $95 \% \mathrm{CI}$ in 2017, 2018, and 2019 was 141.7 (141.1-142.2), 140.8 (140.2-141.3), and 162.7 (162.0-163.2) for the whole Qatar population; 154.2 (153.6-154.7), 105.2 (104.7-105.7), and 176.6 (175.9-177.1) for Qataris; and 134.8 (134.3-135.4), 183.9 (183.3-184.6), and 160.4 (159.8-161.0) for nonQataris, respectively. Table 3 demonstrates the annual ageadjusted standardized incidence rate of osteoporotic hip 
Table 2 Age- and sex-specific incidence rate of osteoporotic hip fracture per 100,000 population distributed according to Qataris vs. non-Qataris over the study period 2017 to 2019 with corresponding $95 \%$ CI

\begin{tabular}{|c|c|c|c|c|c|c|}
\hline \multirow{2}{*}{$\begin{array}{l}\text { Age groups } \\
\text { (years) }\end{array}$} & \multicolumn{2}{|c|}{ Qataris, $n$ (mean IR) } & \multicolumn{2}{|c|}{ Non-Qataris, $n$ (mean IR) } & \multicolumn{2}{|c|}{ Qatar population, $n$ (mean IR) $95 \% \mathrm{CI}$} \\
\hline & Male & Female & Male & Female & Male & Female \\
\hline $40-44$ & $2(9.1)$ & $2(8.0)$ & $7(1.2)$ & $1(0.8)$ & $9(1.5) 0.7803-2.819$ & $3(1.9) 0.652-5.634$ \\
\hline $45-49$ & $1(5.0)$ & $0(0)$ & $12(2.9)$ & $2(2.4)$ & $13(3.0) 1.773-5.192$ & $2(1.9) 0.526-6.991$ \\
\hline $50-54$ & $3(18.0)$ & $3(15.2)$ & $10(4.0)$ & $5(9.9)$ & 13 (4.9) 2.854-8.354 & 8 (11.4) 5.971-22.55 \\
\hline $55-59$ & $2(14.7)$ & $7(42.1)$ & $12(7.5)$ & $6(20.4)$ & 14 (8.1) 2.854-8.354 & 13 (28.2) $16.5-48.3$ \\
\hline $60-64$ & $3(29.8)$ & $6(50.0)$ & $17(26.1)$ & $8(51.4)$ & 20 (26.6) 17.21-41.05 & $14(50.8) 30.24-85.2$ \\
\hline $65-69$ & $6(98.2)$ & $12(177.5)$ & $28(106.6)$ & $11(148.2)$ & $34(105.0) 75.18-146.7$ & 23 (162.2) 108.1-243.2 \\
\hline $70-74$ & $14(296.3)$ & $9(158.8)$ & $24(278.3)$ & $9(267.0)$ & 38 (284.7) 207.5-380.4 & 18 (199.1) 126.0-314.5 \\
\hline $75-79$ & $11(409.1)$ & $14(478.1)$ & $16(427.0)$ & $13(640.3)$ & 27 (419.6) 288.5-609.9 & 27 (544.5) 374.5-791.1 \\
\hline $80+$ & $19(675.1)$ & $27(885.8)$ & $28(992.8)$ & $24(1034.4)$ & 47 (834.1) 627.9-1107 & $51(950.0) 723.3-1247$ \\
\hline
\end{tabular}

*Qatar population includes Qataris and non-Qataris. $I R$, incidence rate; $C I$, confidence interval; $n$, number of hip fracture

Table 3 Annual age-adjusted standardized incidence rate of osteoporotic hip fracture per 100,000 people with the corresponding 95\% confidence interval for population aged $\geq 50$ years

\begin{tabular}{|c|c|c|c|c|c|c|c|c|c|}
\hline \multirow{2}{*}{$\begin{array}{l}\text { Population } \\
\text { groups }\end{array}$} & \multicolumn{3}{|l|}{2017} & \multicolumn{3}{|l|}{2018} & \multicolumn{3}{|l|}{2019} \\
\hline & $\begin{array}{l}\text { Males IR } \\
(95 \% \text { CI })\end{array}$ & $\begin{array}{l}\text { Females IR } \\
(95 \% \mathrm{CI})\end{array}$ & $\begin{array}{l}\text { Total IR } \\
(95 \% \text { CI) }\end{array}$ & $\begin{array}{l}\text { Males IR } \\
(95 \% \text { CI) }\end{array}$ & $\begin{array}{l}\text { Females IR } \\
(95 \% \mathrm{CI})\end{array}$ & $\begin{array}{l}\text { Total IR } \\
(95 \% \text { CI) }\end{array}$ & $\begin{array}{l}\text { Males IR } \\
(95 \% \mathrm{CI})\end{array}$ & $\begin{array}{l}\text { Females IR } \\
(95 \% \text { CI })\end{array}$ & $\begin{array}{l}\text { Total IR (95\% } \\
\text { CI) }\end{array}$ \\
\hline Qataris & $\begin{array}{l}143.7(142.8- \\
144.4)\end{array}$ & $\begin{array}{r}157.0 \\
(156.2-157.9\end{array}$ & $\begin{array}{l}154.2(153 \\
154.7)\end{array}$ & $\begin{array}{l}67.0(66.45- \\
67.64)\end{array}$ & $\begin{array}{r}139.5 \\
(138.8-140.3\end{array}$ & $\begin{array}{l}105.2(1( \\
105.7)\end{array}$ & $\begin{array}{l}-145.6(144.7- \\
146.4)\end{array}$ & $\begin{array}{r}220.0 \\
(219.2-221.1\end{array}$ & $\begin{array}{l}176.6(175.9- \\
177.1)\end{array}$ \\
\hline Non-Qataris & $\begin{array}{l}87.2(86.55- \\
87.89)\end{array}$ & $\begin{array}{r}213.8 \\
(212.8-214.7\end{array}$ & $\begin{array}{l}134.8(134 \\
135.4)\end{array}$ & $\begin{array}{l}-169.8(168.9- \\
170.7)\end{array}$ & $\begin{array}{r}191.0 \\
(190.1-191.9\end{array}$ & $\begin{array}{l}183.9(183 \\
184.6)\end{array}$ & $\begin{array}{l}-256.8(255.7- \\
257.8)\end{array}$ & $-\quad \begin{array}{r}195.4 \\
(194.5-196.3\end{array}$ & $\begin{array}{l}160.4(159.8- \\
161.0)\end{array}$ \\
\hline $\begin{array}{l}\text { Qatar popu- } \\
\text { lation* }\end{array}$ & $\begin{array}{l}112.7(111.9- \\
113.4)\end{array}$ & $\begin{array}{r}183.0 \\
(182.1-183.8\end{array}$ & $\begin{array}{l}141.7(141 \\
142.2)\end{array}$ & $\begin{array}{l}-126.3(125.6- \\
127.1)\end{array}$ & $-\quad \begin{array}{r}155.1 \\
(154.3-155.9\end{array}$ & $\begin{array}{l}140.8(140 \\
141.3)\end{array}$ & $\begin{array}{l}-129.3(128.4- \\
130.1)\end{array}$ & $\begin{array}{r}207.9 \\
(207.0-208.8\end{array}$ & $\begin{array}{l}162.7(162.0- \\
163.2)\end{array}$ \\
\hline
\end{tabular}

*Qatar population includes Qataris and non-Qataris. $I R$, incidence rate; $C I$, confidence interval

fracture per 100,000 individuals, with the corresponding $95 \%$ CI for the population aged $\geq 50$ years.

\section{Discussion}

This is the first nationwide population-based study to estimate the incidence rate of osteoporotic hip fractures in Qatar. We believe that our data are representative of the Qatar population because osteoporotic hip fractures were managed mainly in hospitals operated by HMC, and fractures were captured by ICD-10 coding across all HMC facilities. Interestingly, we found no significant difference in the age-adjusted standardized incidence rate of osteoporotic hip fractures between Qataris and non-Qataris. Expatriates aged $\geq 50$ years are mainly from Arab countries, with a few from South Asian countries. In 2017 and 2019, Qataris had a slightly higher incidence rate than expatriates (154 and 176 vs. 134 and 160, respectively). Our results showed that osteoporotic hip fracture rate was higher in men in the age group (70-75) which was not the case from other reports. We were not able to justify this finding.

Our figures are close to those of regional countries. Based on our data, Qataris had a standardized incidence rate ranging from 154 to 176 per 100,000 people aged $\geq 50$ years, which was slightly less than Kuwaitis, who had a standardized incidence rate from 2009 to 2012, ranging between 161 and 194 per 100,000 inhabitants aged $\geq 50$ years. Kuwait's report included all hip fractures, while our data included only osteoporotic fractures [15]. In Lebanon, the age-standardized annual incidence rates (per 100,000) were 180 in men and 256 in women, which were higher than our rates. The Lebanese data included all hip fractures [16]. In general, the incidence rate of osteoporotic hip fractures in Qatar was comparable to that in regional Middle Eastern countries, and was much lower than that in North America and European countries, where the standardized incidence rate reached $>200$ per 100,000 [17].

Qatar is a small geographical country with a well-established EMR network; this provided an advantage in that we were able to capture all hip fractures that occurred over the 
study period (2017-2019). In addition, our study is one of the few publications that included only osteoporotic hip fractures rather than all hip fractures. We believe that our results provide an accurate estimate of the incidence of osteoporotic hip fractures. We have presented our data as the age-sexspecific incidence rate and age incidence rate standardized to the world population 2010 to enable easy comparison with the figures of other countries.

There are some limitations to this study that should be addressed. First, hip fractures from private hospitals were not counted; however, most, if not all, hip fractures in Qatar were managed by the HMC as all medical services provided by HMC are accessible for Qataris and expatriates without the need for medical insurance coverage. Second, we did not calculate the 30 post-hip fracture mortality rate, which is useful for better decision-making regarding the strategy of osteoporosis prevention management at the level of the whole Qatar population.

\section{Conclusion}

The annual age-adjusted standardized incidence rate of osteoporotic hip fracture per 100,000 inhabitants aged $\geq 50$ years in Qatar was comparable to that in regional countries and much lower than that in North America and European countries.

Funding This study was granted by the Medical Research Center of Hamad Medical Corporation. There was no financial support from any pharmaceutical or medical devices companies.

Data availability All data stored on a secured computer system and available.

Code availability Custom codes were used.

\section{Declarations}

Ethical approval All procedures performed in studies involving human participants were in accordance with the ethical standards of the institutional and/or national research committee and with the 1964 Helsinki declaration and its later amendments or comparable ethical standards. Our study is a retrospective study, and it does not contain any studies with human participants or animals performed by any of the authors. For this type of study, formal consent is not required. This study was granted by the medical research center of Hamad Medical Corporation (HMC) under protocol number 01-21-489. Waiver consent was issued by the institutional review board (IRB) committee and used to review subject's electronic medical records HMC.

\section{Conflicts of interest None.}

Open Access This article is licensed under a Creative Commons Attribution 4.0 International License, which permits use, sharing, adaptation, distribution and reproduction in any medium or format, as long as you give appropriate credit to the original author(s) and the source, provide a link to the Creative Commons licence, and indicate if changes were made. The images or other third party material in this article are included in the article's Creative Commons licence, unless indicated otherwise in a credit line to the material. If material is not included in the article's Creative Commons licence and your intended use is not permitted by statutory regulation or exceeds the permitted use, you will need to obtain permission directly from the copyright holder. To view a copy of this licence, visit http://creativecommons.org/licenses/by/4.0/.

\section{References}

1. Hernlund E, Svedbom A, Ivergard M, Compston J, Cooper C, Stenmark J, McCloskey EV, Jonsson B, Kanis JA (2013) Osteoporosis in the European Union: medical management, epidemiology and economic burden. A report prepared in collaboration with the International Osteoporosis Foundation (IOF) and the European Federation of Pharmaceutical Industry Associations (EFPIA). Arch Osteoporos 8:136

2. Teng GG, Curtis JR, Saag KG (2008) Mortality and osteoporotic fractures: is the link causal, and is it modifiable? Clin Exp Rheumatol 26:S125-137

3. Dyer SM, Crotty M, Fairhall N, Magaziner J, Beaupre LA, Cameron ID, Sherrington C, Fragility Fracture Network Rehabilitation Research Special Interest G (2016) A critical review of the longterm disability outcomes following hip fracture. BMC Geriatr $16: 158$

4. Gullberg B, Johnell O, Kanis JA (1997) World-wide projections for hip fracture. Osteoporos Int 7:407-413

5. Cheung CL, Ang SB, Chadha M et al (2018) An updated hip fracture projection in Asia: the Asian Federation of Osteoporosis Societies study. Osteoporos Sarcopenia 4:16-21

6. Kanis JA, Johnell O, De Laet C, Jonsson B, Oden A, Ogelsby AK (2002) International variations in hip fracture probabilities: implications for risk assessment. J Bone Miner Res 17:1237-1244

7. Dhanwal DK, Dennison EM, Harvey NC, Cooper C (2011) Epidemiology of hip fracture: worldwide geographic variation. Indian J Orthop 45:15-22

8. Dimai HP, Svedbom A, Fahrleitner-Pammer A, Pieber T, Resch H, Zwettler E, Chandran M, Borgstrom F (2011) Epidemiology of hip fractures in Austria: evidence for a change in the secular trend. Osteoporos Int 22:685-692

9. Rosengren BE, Bjork J, Cooper C, Abrahamsen B (2017) Recent hip fracture trends in Sweden and Denmark with age-periodcohort effects. Osteoporos Int 28:139-149

10. Paruk F, Matthews G, Cassim B (2017) Osteoporotic hip fractures in Black South Africans: a regional study. Arch Osteoporos 12:107

11. El Maghraoui A, Ngbanda AR, Bensaoud N, Bensaoud M, Rezqi A, Tazi MA (2013) Age-adjusted incidence rates of hip fractures between 2006 and 2009 in Rabat, Morocco. Osteoporos Int 24:1267-1273

12. El Maghraoui A, Koumba BA, Jroundi I, Achemlal L, Bezza A, Tazi MA (2005) Epidemiology of hip fractures in 2002 in Rabat, Morocco. Osteoporos Int 16:597-602

13. Zebaze RM, Seeman E (2003) Epidemiology of hip and wrist fractures in Cameroon, Africa. Osteoporos Int 14:301-305

14. Armitage P, Berry G, Matthews JNS (2002) Statistical methods in medical research. Blackwell Scientific Publications, Oxford, Boston

15. Azizieh FY (2015) Incidence of hip fracture in Kuwait: a national registry-based study. Arch Osteoporos 10:40

16. Maalouf G, Bachour F, Hlais S, Maalouf NM, Yazbeck P, Yaghi Y, Yaghi K, El Hage R, Issa M (2013) Epidemiology of hip fractures 
in Lebanon: a nationwide survey. Orthop Traumatol Surg Res 99:675-680

17. Cheng SY, Levy AR, Lefaivre KA, Guy P, Kuramoto L, Sobolev B (2011) Geographic trends in incidence of hip fractures: a comprehensive literature review. Osteoporos Int 22:2575-2586
Publisher's note Springer Nature remains neutral with regard to jurisdictional claims in published maps and institutional affiliations. 